\title{
8
}
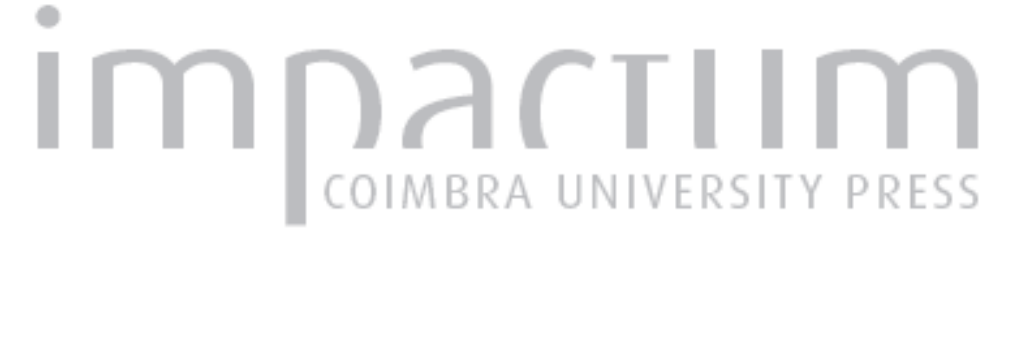

\section{O comportamento hidrológico do rio Mondego perante valores de precipitação intensa, em Coimbra}

Autor(es): $\quad$ Louro, Sílvia; Lourenço, Luciano

Publicado por: Associação Portuguesa de Riscos, Prevenção e Segurança

URL persistente:

URI:http://hdl.handle.net/10316.2/39089

DOI:

DOI:http://dx.doi.org/10.14195/1647-7723_12_3

Accessed : $\quad$ 26-Apr-2023 15:03:12

A navegação consulta e descarregamento dos títulos inseridos nas Bibliotecas Digitais UC Digitalis, UC Pombalina e UC Impactum, pressupõem a aceitação plena e sem reservas dos Termos e Condições de Uso destas Bibliotecas Digitais, disponíveis em https://digitalis.uc.pt/pt-pt/termos.

Conforme exposto nos referidos Termos e Condições de Uso, o descarregamento de títulos de acesso restrito requer uma licença válida de autorização devendo o utilizador aceder ao(s) documento(s) a partir de um endereço de IP da instituição detentora da supramencionada licença.

Ao utilizador é apenas permitido o descarregamento para uso pessoal, pelo que o emprego do(s) título(s) descarregado(s) para outro fim, designadamente comercial, carece de autorização do respetivo autor ou editor da obra.

Na medida em que todas as obras da UC Digitalis se encontram protegidas pelo Código do Direito de Autor e Direitos Conexos e demais legislação aplicável, toda a cópia, parcial ou total, deste documento, nos casos em que é legalmente admitida, deverá conter ou fazer-se acompanhar por este aviso.

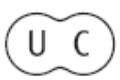




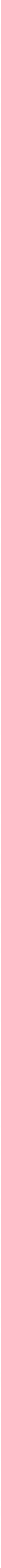




\title{
O comportamento hidrológico do rio Mondego perante valores de precipitação intensa, em Coimbra ${ }^{1}$
}

\author{
Sîlvia Louro* \\ Luciano Lourenço**
}

\begin{abstract}
Resumo:
A compreensão dos fenómenos naturais associados a riscos climático-meteorológicos e hidrológicos pretende ser um contributo para a sua prevenção. Neste âmbito, estabeleceram-se parâmetros de risco, quanto a cheia e inundação, para as estações de referência, em Coimbra e foram delimitados espaços que devem ser considerados de restrição e de precaução, quanto à sua ocupação.

Palavras-chave:

Caudal natural, caudal regularizado, cheia "significativa", risco de cheia, perigo de inundação, vulnerabilidade.
\end{abstract}

\section{Résumé:}

La compréhension des phénomènes naturels associés aux risques climat-météorologiques et hydrologiques, prétendêtre un contribut pour sa prévention. Dans ce point de vue, on aétablit des paramètres de risque par rapport à la crue et à l'inondation, pour les saisons de référence, à Coimbra, et ont été délimités des espaces qui doivent être considérés de restriction et de précaution, en se qui concerne à sa occupation humaine.

Mots clés:

Débit naturel, débit régularisé, crue «significative», risque de crue, danger de inondation, vulnérabilité.

\begin{abstract}
:
The understanding of natural phenomenon associated to climatic-meteorological and hydrologic risks intends to be a contribution to its prevention. In reference to this, risks parameters were established with regard to flood and inundation, in terms of regulating seasons, in Coimbra, and places that must be considered restricted and precautional areas, in human terms, were delimited.

Key-words:

Natural discharge, regulated discharge, "significative flood", risk of flood, danger of inundation, vulnerability.
\end{abstract}

\section{Introdução}

A bacia do Mondegoé limitada a Norte pelas bacias dos rios Vouga e Douro, a Este pelas dos rios Douro e Tejo e a Sul pelas dos rios Lis e Tejo (Fig. 1).Éa maior bacia totalmente incluída em território português, com "orientação NE-SW, [semelhante à dos] grandes rios da fachada atlântica da Península Ibérica" ( $O$. RIBEIRO, et al., 1994, p. 522).

Desenvolve-se "em grande parte na encosta NW da Cordilheira Central e nas depressões tectónicas

1 Com base na tese de mestrado intitulada "Condições meteorológicas com efeitos de inundação. O exemplo da bacia do Mondego".

* Mestre em Geografia, Especialização em Geografia Física e Estudos Ambientais.

** Instituto de Estudos Geográficos. Faculdade de Letras da Universidade de Coimbra. de sopé" (ob. cit., p. 523), limitada a SE pela cordilheira Central e a NW pela serra do Caramulo.

Entre Coimbra e Figueira da Foz, o rio atravessa a planície aluvionar designada "campos do Mondego", com uma área de cerca de 15000 ha. Neste troço o Mondego toma a designação de "Baixo Mondego", "com um desenvolvimento de cerca de $45 \mathrm{Km}$ " (A. QUINTELA, 1986, p. 1026).

Nos espaços ribeirinhos do Mondego, de Coimbra para jusante, sujeitos a maior pressão humana, cada vez mais se pratica uma ocupação dos leitos de inundação. Desde a construção da barragem da Aguieira - construída no período compreendido entre 1972 e 1982 (L. LOURENÇO, 1986, p. 52) -, a população ribeirinha passou a depositar toda a confiança na regularização do rio, esquecendo o risco de cheia e de inundação. 


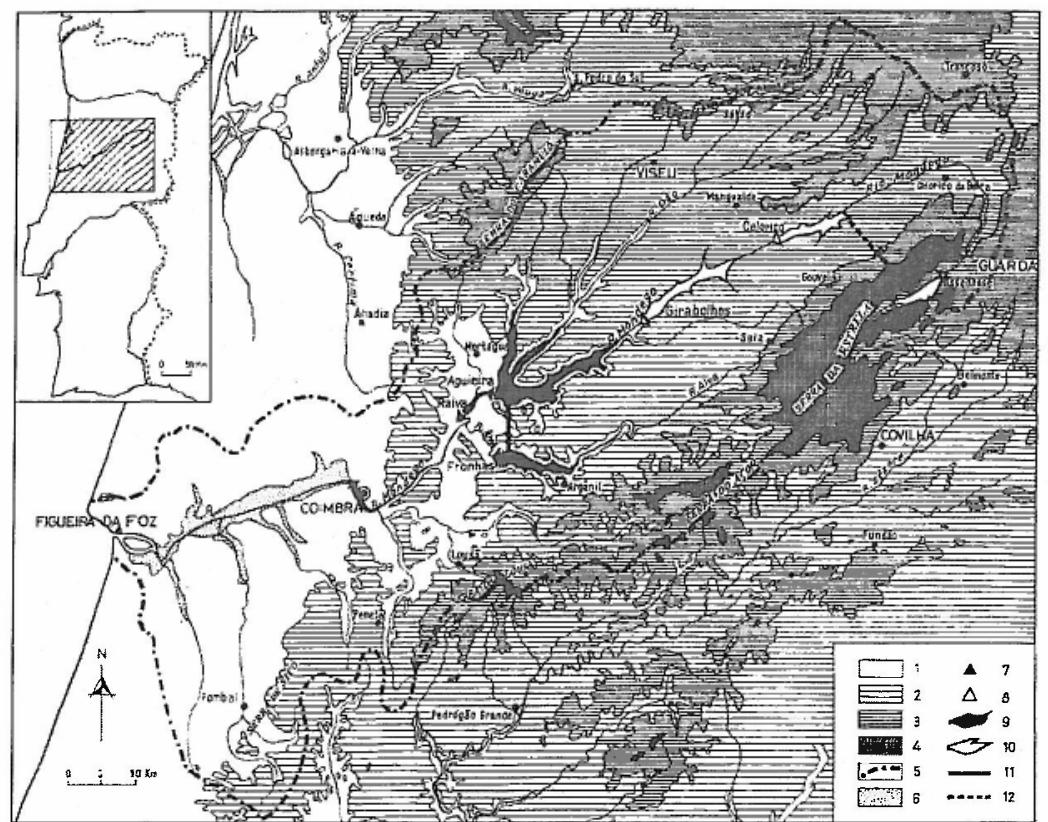

Figura 1 - Localização e hipsometria da bacia hidrográfica do rio Mondego.

Legenda: 1 - altitudes inferiores a $200 \mathrm{~m}$; 2 - altitudes de 200 a $600 \mathrm{~m} ; 3$ - altitudes de 600 a $1000 \mathrm{~m} ; 4$ - altitudes superiores a $1000 \mathrm{~m}$; 5 - limite da bacia hidrográfica do rio Mondego; 6 - campos do baixo Mondego; 7 - barragens construídas; 8 - barragens projectadas; 9 - albufeiras já criadas; 10 - albufeiras planeadas; 11 - túnel executado; 12 - túnel previsto. Fonte: L. LOURENÇO, 1986, p. 46.
Em período de regularização, a situação de crise mais grave ocorreu a 27 de Janeiro de 2001 , quando o caudal máximo instantâneo foi de $1910,7 \mathrm{~m}^{3} / \mathrm{s}$ no Açude-Ponte de Coimbra, com efeitos catastróficos no Baixo Mondego, principalmente ao nível da agricultura, infra-estruturas e equipamentos, incluindo habitações. No entanto, a cheia de 1948 , que fora muito mais excepcional que a de 2001 , uma vez que, os aproximadamente $4000 \mathrm{~m}^{3} / \mathrm{s}$ são bem superiores aos $3000 \mathrm{~m}^{3} / \mathrm{s}$ (ambos como caudal natural), teve consequências bem menos nefastas, por então existir uma "cultura de risco de cheias" que se perdeu com a regularização. Aquela situação de crise vivida em 2001 veio salientar a vulnerabilidade dos espaços aparentemente salvaguardados.

\section{Metodologia e séries de dados}

Neste contexto, foi estudado o comportamento hidrológicodorioMondego,emsecções dereferênciadeCoimbra: a Ponte de Santa Clara, em período de caudal natural e em função dos dados existentes, de 1947/48 a 1984/85 e os caudais efluentes do Açude-Ponte, em período de caudal regularizado, de 1985/86 a 2000/01.

São apresentados os resultados da análise da evolução dos caudais do rio Mondego na Ponte de Santa Clara e no Açude-Ponte, seguindo-se o comportamento hidrológico do rio Mondego aquando de precipitações intensas, em Coimbra. Foi também estabelecida relação entre precipitação acumulada e caudais de cheia "significativa" e traçadas categorias de riscode cheia e perigo de inundação para Coimbra, de acordo com situações de crise referentes a cheias e inundações analisadas. Neste âmbitoé apresentado um cartograma de espaços inundáveis, como sugestão para a prevenção do risco de cheia e de inundação, destacando áreas de "precaução" e de "restrição".

Os dados udométricos e registos hidrométricos (caudais médios e máximos instantâneos) utilizados, são do Instituto Geofísico da Universidade de Coimbra (IGUC), das publicações da Direcção Geral dos Serviços Hidráulicos (DGSH) e Eléctricos (DGSHE) e do Instituto Nacional daÁgua(INAG), noqual se insere também o Núcleo de Apoio Centro (NAC). A dificuldade na obtenção de séries de dados hidrométricos completas da Ponte de Santa Clara, justifica as lacunas na representação de alguns caudais médios e instantâneos.

\section{Resultados e sua discussão}

\section{Evolução dos caudais do rio Mondego na Ponte de Santa Clara e no Açude-Ponte, em Coimbra}

No período de $1947 / 48$ a 1984/85, a tendência dos caudais médios diários (máximos anuais) foi de decréscimo. Este foi ainda mais acentuado para os caudais máximos instantâneos anuais (QMI) (Fig. 2). A causa desta evolução pode atribuir-se, em parte, ao papel regularizador do sistema de albufeiras do rio Mondego, com especial destaque para o da Aguieira-Fronhas, pela sua capacidade de armazenamento, nos últimos anos daquele período. De 1985/86 a 2000/ 101 evidencia-se a irregularidade dos caudais registados. 


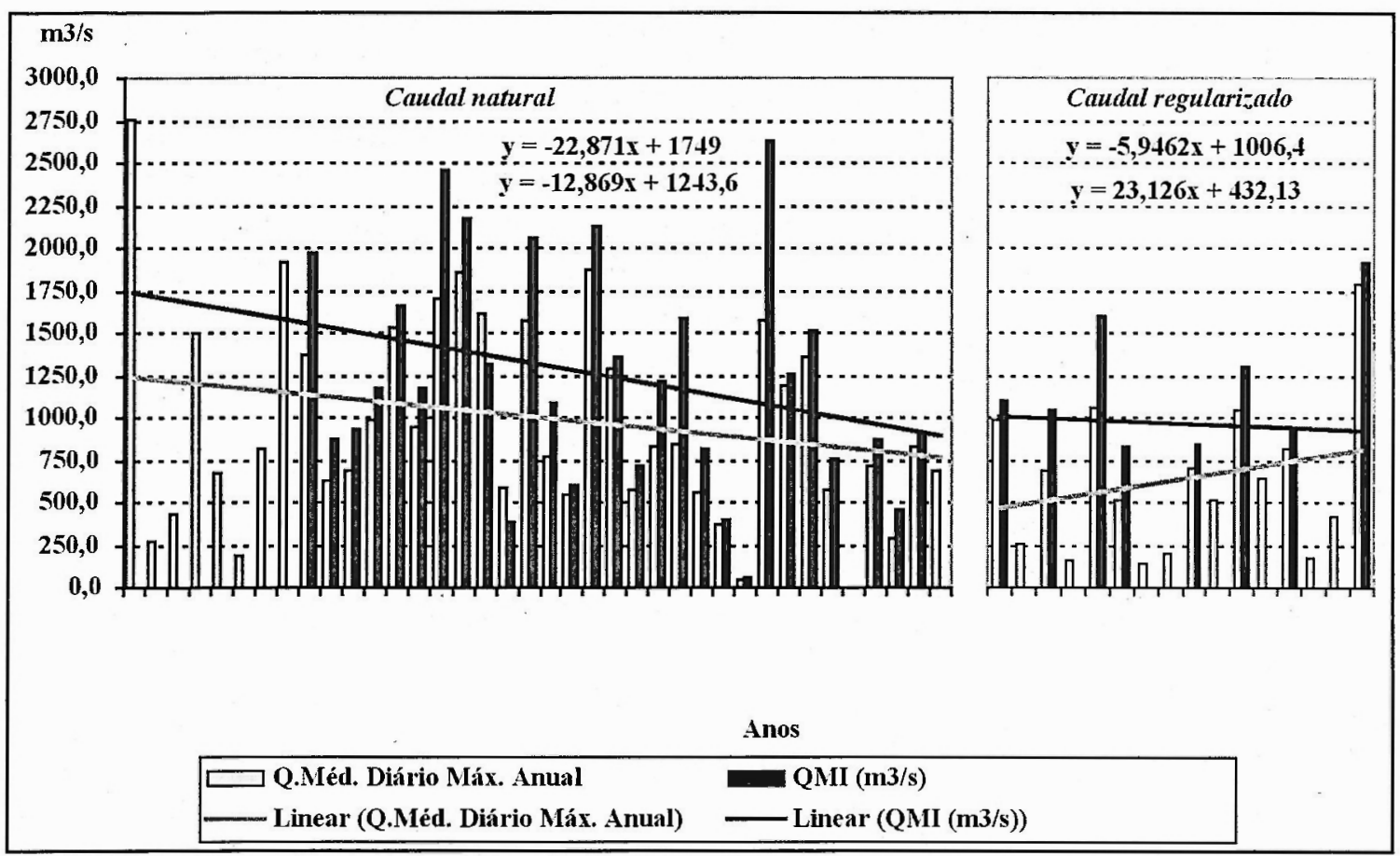

Figura 2 - Evolução dọs caudais médios diários máximos e máximos instantâneos, anuais, de 1947/48 a 2000/2001. Fonte: DGSH, INAG, NAC

Mesmo em período de caudal regularizado, nos Invernos mais chuvosos, o rio seguiu mais caudaloso, atingindo elevados valores de caudais de cheia (mensais e anuais) que, em três anos, ultrapassaram $1200 \mathrm{~m}^{3} /$ $\mathrm{s}$, o valor considerado como caudal de cheia centenária regularizado. No total da amostra (de 1955/2001), na maioria dos anos, o valor dos caudais máximos instantâneos (QMI) anuais estiveram abaixo de 1200 $\mathrm{m}^{3} / \mathrm{s}$ (Fig. 3). No período de caudais em regime natural, salienta-se também a frequência de valores acima de $1201 \mathrm{~m}^{3} / \mathrm{s}$ e ainda um ano com valores registados entre 2501 e $3000 \mathrm{~m}^{3} / \mathrm{s}$ - concretamente $2635,21 \mathrm{~m}^{3} / \mathrm{s}$ a 14 de Janeiro de 1977 . Este terá sido o segundo maior valor de QMI anual dos últimos 100 anos, pois como foi referido anteriormente, em Janeiro de 1948 terá ocorrido um pico hidrométrico ${ }^{2}$ que se estima superior a $3000 \mathrm{~m}^{3} / \mathrm{s}$.

Em terceiro lugar está o de 27 de Janeiro de 2001, que atingiu $1910,7 \mathrm{~m}^{3} / \mathrm{s}$. No período correspondente ao de caudal regularizado e, sabendo que com o

\footnotetext{
$\mathrm{Q}=\left(100+4 \mathrm{H}^{2}\right)(\mathrm{H}-0,40)^{3 / 2}$, segundo DGSHE, 1936, p. 51. Q corresponde ao caudal máximo instantâneo $\mathrm{e} H$ à altura hidrométrica máxima. Sabendo que a altura máxima na Ponte de Sta Clara, em Coimbra, foi de $6,48 \mathrm{~m}^{3} / \mathrm{s}$, o pico hidrométrico poderá ter ultrapassado os $4000 \mathrm{~m}^{3} / \mathrm{s}$, pois quando aplicada a fórmula da Curva de Vazão, o valor do caudal obtido é de $4017,24 \mathrm{~m}^{3} / \mathrm{s}$.
}

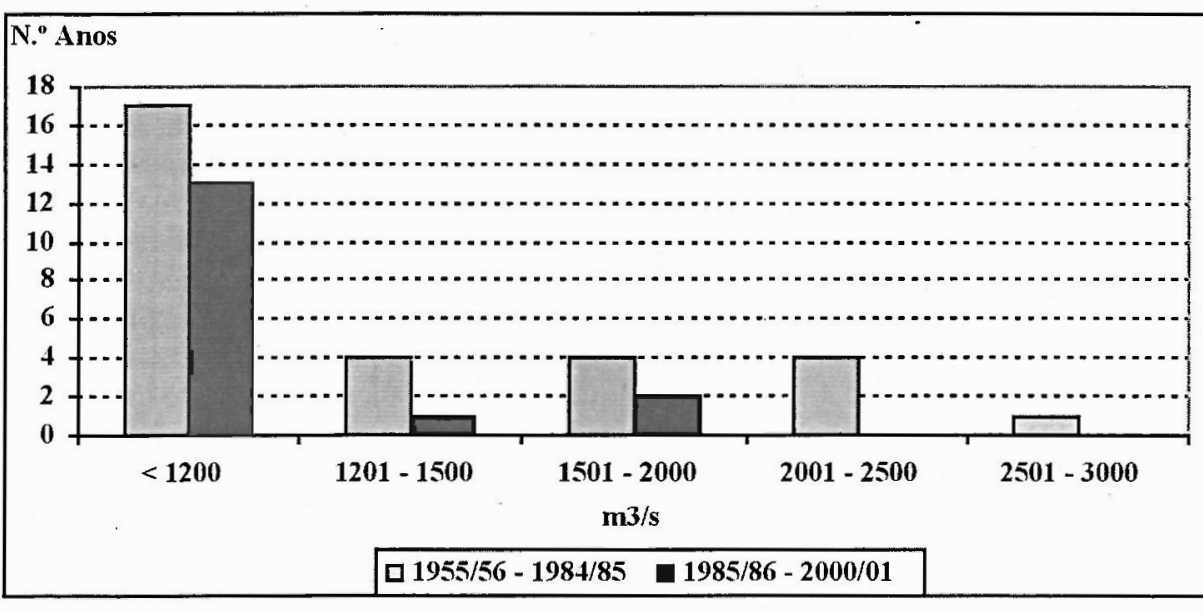

Figura 3 - Variação dos valores dos caudais máximos instantâneos anuais, de $1955 / 56$ a $2000 / 2001$. Fonte: DGSH, INAG, NAC 
sistema de regularização do Mondego o caudal de cheia centenária em Coimbra foi reduzido para 1200 $\mathrm{m}^{3} / \mathrm{s}$, verificamos que este valor foi ultrapassado em três anos. Foi o caso de 27 de Janeiro de 2001, 21 de Dezembrode 1989 (com $\left.1599 \mathrm{~m}^{3} / \mathrm{s}\right)$ e de 26 de Dezembro de 1995 (com 1302,9 m³/s). Contudo, é notório o efeito regularizador das barragens a montante da cidade, pois, apesarda proximidade, nãoforam ultrapassados valores de $2000 \mathrm{~m}^{3} / \mathrm{s}$. Este valor é referido por A. LENCASTRE e F.M. FRANCO (1984, p.395) como o de cheia milenar, que deverá ser assegurado para defesa da cidade de Coimbra contra inundações.

\section{O comportamento hidrológico do rio Mondego perantevalores de precipitação intensa, em Cointbra}

Em Coimbra, oMondego não deve ser genericamente classificado como de carácter fortemente torrencial, porque apesar da amplitude dos seus módulos mensais e anuais, a metodologia utilizada no estudo realizado demonstrou que as maiores alturas hidrométricas correspondem a aumentos progressivos do caudal - de que é exemplo a situação de 2000/2001 (fig. 4) e que apenas algumas das precipitações máximas diárias anuais é que proporcionam picos de cheia de carácter torrencial, à semelhança do que ocorre nas grandes bacias (C. RAMOS e E. REIS, 2001, p. 60).

Nas secções de referência (Ponte de Sta Clara e Açude-Ponte, de Coimbra), as cheias que são progressivas, são menos violentas do que as cheias rápidas, mas mais prolongadas. $O$ tempo de concentração é superior em grandes bacias, daí que estas sejam mais propícias a "cheias progressivas", enquanto que as cheias e inundações rápidas são mais frequentes nas pequenas bacias.

Isto significa ainda que, muitas vezes, em linguagem corrente, o conceito de cheia se associa à inundação das áreas marginais dos rios e aos danos aí causados, não se considerando apenas o seu sentido estritamente hidrológico, ou seja, quando a precipitação dá origem à ocorrência de escoamento superficial directo, que se traduz na formação de um hidrograma de cheia (A. LENCASTRE e F. M. FRANCO, 1984, p. 284), fazendo-as corresponder a um aumento progressivo do caudal do rio e não a um aumento brusco.

De entre as cheias consideradas "significativas" - que caracterizámos como estando acima do $9^{\circ}$ decil do mês de maior caudal ${ }^{3}$-, as de maior magnitude, por ordem decrescente, foram as de 1948, 1977, 1961/62 e 2001. Estas surgiram na sequência de meses, do Outono e Inverno, chuvosos ou muito chuvosos e com caudais muito abundantes a excessivamente abundantes (segundo a classificação elaborada).

\footnotetext{
Desenvolvido a partir do parâmetro utilizado por C. RAMOS e E. REIS (2001, p.73).
}

Actualmente, em Coimbra, em período de regularização, quando existe uma sequência de meses chuvosos ou muito chuvosos e com caudais pelo menos muito abundantes, a vigilância deve aumentar, porque aumenta o risco de cheias que, no Baixo Mondego, se poderá tornar em perigo de inundação (Tab. l).

\section{Relação entre precipitação acumulada e caudais de cheia "significativa"}

Partindo da ocorrência de caudais de cheia na sequência pluviosa em que se registou o valor de precipitação máxima diária anual, foi estabelecida uma sobreposição entre dias de cheia "significativa" e precipitação acumulada, tendo como início da representação, o mês de Outubro.

Ao relacionar a precipitação acumulada com os caudais de cheia "significativa", evidenciou-se o carácter fortemente pluvial do rio Mondego, ou seja, ao início da primeira sequência de dias de cheia corresponderam os aumentos bruscos da precipitação acumulada, o que geralmente termina quando se dá uma estabilização do ritmo da precipitação.

Em regime não regularizado, os caudais e níveis máximos com maior risco de inundação ocorreram a partir de valores de precipitação acumulada em torno dos $400 \mathrm{~mm}$, logo em Novembro ou apenas em Janeiro. Exemplos de Novembro são 1963 e 1976, em que a concentração de precipitação foi acentuada e repentina, em particular para 1963 , o que originou forte escoamento directo.

Em Janeiro de 1948 e 1962, a sequência de precipitação constante e intensa, foi também condição principal para a ocorrência de caudal de cheia e forte inundação, especialmente em 1948 (S. LOURO, 2004, p. 86).

Dos dias de cheia "significativa" ocorridos nos anos hidrológicos sem caudal regularizado, e contabilizada a sua frequência mensal, os meses de Dezembro e Janeiro destacam-se com maior número de dias de cheia, seguindo-se Fevereiro e em quarto lugar, Novembro.

Em período de regularização do caudal, houve maior susceptibilidade de ocorrência de caudal de cheia em Dezembro e Janeiro, bem como o aumento do risco de inundação ao longo do Inverno devido à precipitação acumulada e menor capacidade de retenção dos solos e de encaixe das albufeiras (S. LOURO, 2004, p. 90). Notámos que em situação de regularização só ocorreram caudais de cheia a partir dos $500 \mathrm{~mm}$, situação que só se verifica de Dezembro em diante.

O facto dos caudais de cheia se verificarem agora a partir de 500 e não $400 \mathrm{~mm}$, demonstra a acção de regularização dos caudais. No entanto, o perigo das cheias era já eminente no início de Dezembro de 2000. No dia 7 de Dezembro de 2000, às 21h, 


\begin{tabular}{|c|c|c|c|c|c|c|c|c|c|c|c|c|c|c|c|}
\hline & \multirow[b]{2}{*}{ Ano } & \multicolumn{2}{|c|}{ Prec. Máx. D. A. } & \multirow{2}{*}{$\begin{array}{l}\text { Máx. da Seq." } \\
\text { (Por ordem) }\end{array}$} & \multirow{2}{*}{ Máx. Inst. } & \multirow[b]{2}{*}{$\begin{array}{l}\text { Seco } \\
\end{array}$} & \multirow[b]{2}{*}{ Chuvoso } & \multirow[b]{2}{*}{\begin{tabular}{|l|} 
Mt. Chuvoso \\
\end{tabular}} & \multirow[b]{2}{*}{ Exces. Chuv. } & \multirow[b]{2}{*}{ Inferior } & \multirow[b]{2}{*}{ Superior } & \multirow[b]{2}{*}{ Escasso } & \multirow[b]{2}{*}{ Abundante } & \multirow[b]{2}{*}{ Mt. Abund. } & \multirow[b]{2}{*}{ Exces. Ab. } \\
\hline & & Dia-Mês & $(\mathrm{mm})$ & & & & & & & & & & & & \\
\hline \multirow{13}{*}{ IV } & 1975 & 29-Set & 52,2 & 8,0 & & $\mathrm{Ag}$ & $\mathrm{S}$ & - & - & $\mathrm{Ag}$ & $\mathrm{S}$ & $\mathrm{S}$ & - & - & - \\
\hline & 1993 & 17-Set & 69,0 & 10,0 & & $\mathrm{Ag}$ & - & $S$ & - & - & $\mathrm{Ag}, \mathrm{S}$ & $\mathrm{S}$ & - & - & - \\
\hline & 1949 & 24-Out & 52,1 & 35,5 & & - & $\mathrm{S}, \mathrm{O}$ & - & - & - & $\mathrm{S}$ & 0 & - & - & - \\
\hline & 1956 & 21-Mai & 54,5 & 36,0 & & $\mathrm{O}, \mathrm{N}, \mathrm{F}$ & $\mathrm{D}, \mathrm{J}, \mathrm{Mc}$ & A, Mai & - & O, F, Mai & $\mathrm{N}, \mathrm{D}, \mathrm{J}, \mathrm{Mç}, \mathrm{A}$ & $\mathrm{O}, \mathrm{N}, \mathrm{J}, \mathrm{F}$ & $\mathrm{D}, \mathrm{Mc}, \mathrm{A}, \mathrm{Mai}$ & - & - \\
\hline & 1990 & 06-Abr & 51,8 & 118,6 & & $\mathrm{~F}, \mathrm{Mç}$ & $\mathrm{O}, \mathrm{N}, \mathrm{D}, \mathrm{J}, \mathrm{A}$ & - & - & $\mathrm{O}, \mathrm{F}, \mathrm{Mc}, \mathrm{A}$ & $\mathrm{N}, \mathrm{D}$ & $\mathrm{O}, \mathrm{J}, \mathrm{F}, \mathrm{Mç}, \mathrm{A}$ & $\mathrm{N}$ & - & $\mathrm{D}$ \\
\hline & 1986 & 14-Dez & 53,7 & 133,0 & & $\mathrm{O}, \mathrm{N}, \mathrm{D}$ & - & - & - & $\mathrm{N}, \mathrm{D}$ & - & $\mathrm{O}, \mathrm{N}, \mathrm{D}$ & - & - & - \\
\hline & 1976 & $25-$ Set & 65,7 & 166,0 & & - & - & $\mathrm{Ag}, \mathrm{S}$ & - & - & $\mathrm{Ag}, \mathrm{S}$ & $\mathrm{S}$ & - & - & - \\
\hline & 1953 & 11-Out & 55,4 & 240,0 & & $\mathrm{~S}$ & - & 0 & - & - & $\mathrm{S}, \mathrm{N}$ & $\mathrm{O}$ & - & - & - \\
\hline & 1979 & 24-Dez & 56,3 & 379,5 & & $\mathrm{~N}$ & $\mathrm{D}$ & 0 & - & $\mathrm{N}$ & $\mathrm{O}, \mathrm{D}$ & $\mathrm{D}$ & $\mathrm{O}, \mathrm{N}$ & - & - \\
\hline & 1950 & 04-Fev & 54,6 & 428,0 & & $\mathrm{D}, \mathrm{J}$ & $\mathrm{S}, \mathrm{O}, \mathrm{N}, \mathrm{F}$ & - & - & - & $\mathrm{S}, \bar{N}, \mathrm{~F}$ & $\mathrm{O}, \mathrm{N}, \mathrm{D}, \mathrm{J}, \mathrm{F}$ & - & - & - \\
\hline & 1974 & 28-Jun & 57,4 & 504,4 & & $\mathrm{O}, \mathrm{N}, \mathrm{D}, \mathrm{Mç}, \mathrm{A}$ & $\mathrm{J}, \mathrm{F}, \mathrm{Mai}, \mathrm{Jn}$ & - & - & $\mathrm{N}, \mathrm{D}, \mathrm{A}$ & $\mathrm{O}, \mathrm{J}, \mathrm{F}, \mathrm{Mç}, \mathrm{Mai}, \mathrm{Jn}$ & $\mathrm{O}, \mathrm{N}, \mathrm{D}, \mathrm{Mç}, \mathrm{A}$ & $\mathrm{J}, \mathrm{F}, \mathrm{Jn}$ & - & - \\
\hline & 1978 & $16-\mathrm{Fev}$ & 50,5 & 537,8 & & $\mathrm{~N}, \mathrm{~J}$ & $\mathrm{O}, \mathrm{D}, \mathrm{F}$ & - & - & - & $\mathrm{O}, \mathrm{D}, \mathrm{J}, \mathrm{F}$ & $\mathrm{N}, \mathrm{J}$ & $\mathrm{O}, \mathrm{D}, \mathrm{F}$ & - & - \\
\hline & 1951 & 05-Nov & 55,0 & 601,4 & & $\mathrm{~S}, \mathrm{O}$ & - & $\mathrm{N}$ & - & $\mathrm{O}$ & $\mathrm{S}, \mathrm{N}$ & 0 & - & $\mathrm{N}$ & - \\
\hline \multirow{5}{*}{ III } & 1960 & $03-\mathrm{Abr}$ & 63,9 & 766,1 & & $\mathrm{O}, \mathbf{J}$ & $\mathrm{N}, \mathrm{A}$ & $\mathrm{D}, \mathrm{F}, \mathrm{M} \subsetneq$ & - & $\mathrm{J}, \mathrm{A}$ & $\mathrm{O}, \mathrm{N}, \mathrm{D}, \mathrm{F}, \mathrm{Mç}$ & $\mathrm{O}$ & $\mathrm{N}, \mathrm{J}, \mathrm{A}$ & $\mathrm{F}, \mathrm{Mç}$ & $\mathrm{D}$ \\
\hline & 1959 & 20-Nov & 49,8 & 798,0 & & 0 & $\mathrm{~N}$ & - & - & - & $\mathrm{O}, \mathrm{N}$ & $\mathrm{O}$ & $\mathrm{N}$ & - & - \\
\hline & 1954 & 12-Mar & 61,0 & 813,2 & & $\mathrm{~S}, \mathrm{~N}, \mathrm{D}, \mathrm{J}$ & - & $\mathrm{O}, \mathrm{Mc}$ & - & $\mathrm{N}, \mathrm{D}, \mathrm{J}, \mathrm{F}$ & $\mathrm{S}, \mathrm{O}, \mathrm{Mç}$ & $\mathrm{O}, \mathrm{N}, \mathrm{D}, \mathrm{J}, \mathrm{F}$ & $\mathrm{Mc}$ & - & - \\
\hline & 1958 & 19-Dez & 50,5 & 984,0 & 1169,0 & $\mathrm{~N}$ & $\mathrm{O}, \mathrm{D}$ & - & - & $\mathrm{O}, \mathrm{N}$ & $\mathrm{D}$ & $\mathrm{O}, \mathrm{N}$ & $\mathrm{D}$ & - & - \\
\hline & 1973 & 17-Jan & 57,3 & 1007,2 & 1580,0 & - & $\mathrm{O}, \mathrm{N}, \mathrm{D}, \mathrm{J}$ & - & - & $\mathrm{J}$ & $\mathrm{O}, \mathrm{N}$ & $\mathrm{O}, \mathrm{N}, \mathrm{D}$ & $J$ & - & - \\
\hline \multirow{4}{*}{ II } & 1989 & 21-Dez & 69,8 & 1052,4 & 1599,0 & - & $\mathrm{O}, \mathrm{N}, \mathrm{D}$ & - & - & $\mathrm{O}$ & $\mathrm{N}, \mathrm{D}$ & 0 & $\mathrm{~N}$ & - & D \\
\hline & 1977 & 14-Jan & 53,7 & 1571,2 & 2635,2 & - & $\mathrm{N}, \mathrm{D}, \mathrm{J}$ & $\mathrm{Ag}, \mathrm{S}, \mathrm{O}$ & - & $\mathrm{N}$ & $\mathrm{Ag}, \mathrm{S}, \mathrm{O}, \mathrm{D}, \mathrm{J}$ & - & $\mathrm{D}$ & $\mathrm{O}, \mathrm{N}, \mathrm{J}$ & - \\
\hline & 1963 & 15-Nov & 75,8 & 1616,0 & & $\bar{O}$ & $S$ & - & $\mathrm{N}$ & $\mathrm{S}, \mathrm{O}$ & $\mathrm{N}$ & $\mathrm{O}$ & - & - & $\mathrm{N}$ \\
\hline & $1961 / 62^{*}$ & 30-Dez & 79,3 & 1707,0 & 2457,0 & $\mathrm{O}$ & $\mathrm{N}, \mathrm{D}, \mathrm{J}$ & - & - & $\mathrm{J}$ & $\mathrm{N}, \mathrm{D}$ & $\mathrm{O}$ & $\mathrm{N}, \mathrm{D}$ & $\mathrm{J}$ & - \\
\hline \multirow[t]{2}{*}{ I } & 2001 & 27-Jan & 58,0 & 1778,7 & 1910,7 & - & $\mathrm{O}, \mathrm{N}$ & $\mathrm{D}, \mathrm{J}$ & - & 0 & $\mathrm{~N}, \mathrm{D}, \mathrm{J}$ & $\mathrm{O}$ & - & $\mathrm{N}$ & $\mathrm{D}, \mathbf{J}$ \\
\hline & 1948 & 29-Jan & 56,0 & 2758,0 & & $\mathrm{O}, \mathrm{N}, \mathrm{D}$ & - & $\mathrm{J}$ & - & $\mathrm{O}, \mathrm{N}, \mathrm{D}$ & $\mathrm{J}$ & $\mathrm{O}, \mathrm{N}, \mathrm{D}$ & - & $J$ & - \\
\hline
\end{tabular}

Fonte: DGSH, INAG, NAC; IGUC

$\square$ "Caudal de cheia significativa"

* Continuidade da sequência de Dezembro para Janeiro.

Mês seco: precipitação inferior à média "normal";chuvoso: precipitação superior à média "normal";muito chuvoso: dobro da precipitação média "normal"; 


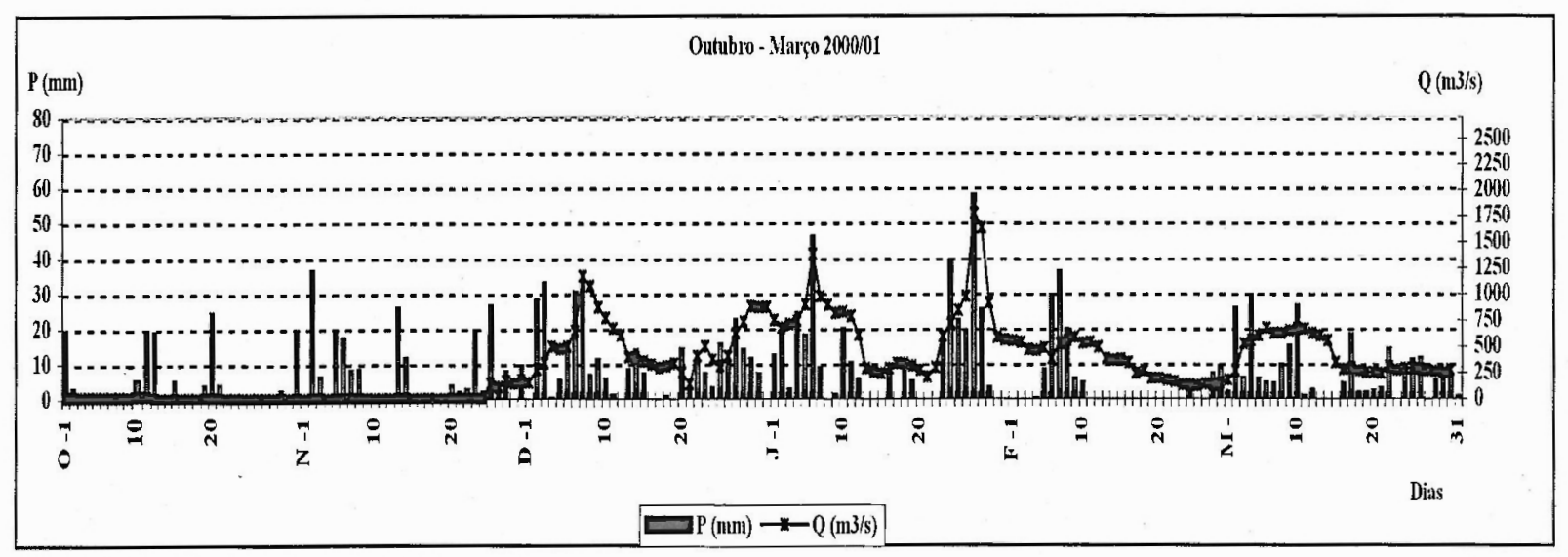

Figura 4 - Distribuição diária da precipitação e dos caudais nos meses de Outubro a Março (Coimbra - IGUC e Açude-Ponte), no período chuvoso de 2000/01. Fonte: IGUC, INAG, NAC.

registou-se uma cota de $18,40 \mathrm{~m}$, com caudais afluente e efluente de $1599 \mathrm{~m}^{3} / \mathrm{s}$, o que proporcionou quatro dias de cheia "significativa", de 7 a 10 de Dezembro (Fig. 4).

De 28 de Dezembro a 11 de Janeiro, na sequência de outro período chuvoso e devido à incapacidade de retenção por parte do solo e das albufeiras, registouse uma série de 15 dias de cheia "significativa". No dia 5 de Janeiro a altura topográfica das águas do rio no Açude-Ponte de Coimbra encontrava-se abaixo da cota considerada normal $(18 \mathrm{~m})$. No entanto, no dia 6 , às 6 h, a cota era de $18,20 \mathrm{~m}$, com um caudal afluente de $1624,9 \mathrm{~m}^{3} / \mathrm{s}$.

Em situação de excesso hídrico, associado ao prolongamentodos episódios chuvosos, poderão ocorrer outras situações de risco, como as que originam movimentações em massa nas vertentes.

No período de Outono-Inverno de 2000/01, foram noticiadas diversas situações de movimentos de terreno, registadas um pouco por todo o país. Em Coimbra, no dia 27 de Dezembro de 2000, ocorreu um deslizamento, num volume de terras de cerca de $4000 \mathrm{~m}^{3}$, arrastando o coberto vegetal. Para além das causas antrópicas, a elevada quantidade de precipitação registada até então, terá sido a grande impulsionadora desta movimentação em massa (L. LOURENÇO, L. LEMOS, 2001, p. 93), uma vez que desde 1 de Outubro até 27 de Dezembro, o valor de precipitação acumulada, ultrapassou os $600 \mathrm{~mm}$ (fig. 5) - mais de metade do total anual médio, em Coimbra. Dezembro, que foi um mês "muito chuvoso" (com valor superior ao dobro da média), foi antecedido por dois meses "chuvosos" (com precipitação superior à "normal"). Para além de intensa, a precipitação foi também frequente, pois em Novembro e Dezembro, onúmero de dias de precipitação foi superior ao "normal" (Tab. I).
Em termos de caudal médio, Novembro foi um mês "muito abundante" e Dezembro e Janeiro foram "excessivamente abundantes"- com caudal superior ao triplo do valor "normal" (Tab. I).

A 27 de Janeiro de 2001, no Açude-Ponte de Coimbra o caudal máximo diárioe máximo instantâneo registado foram de $1910,7 \mathrm{~m}^{3} / \mathrm{s}$, o que correspondeu a um aumento brusco da precipitação acumulada, agravado pela queda de $58 \mathrm{~mm}$ de precipitação - a máxima diária do ano. Tivemos, assim, seis dias de cheia "significativa", de 24 a 29 de Janeiro.

Tanto o maior pico de cheia como o maior risco de inundação, que passou a crise, corresponderam aos $1000 \mathrm{~mm}$ de precipitação acumulada, atingidos a 27 de Janeiro de 2001 (Fig. 5), valor queé semelhante aoda média "normal" da precipitação anual em Coimbra.

Para além do facto da precipitação instantânea se repercutir directamente no caudal máximo instantâneo (QMI), a precipitação acumulada tem, nas secções fluviais estudadas, maior influência sobre o caudal diário, porque aumenta continuamente o caudal do rio, contribuindo desta forma para a formação de cheias progressivas. São exemplos elucidativos, os de 1948, 2001, 1961 e 1963, comos caudais de cheia "significativa" mais elevados da série (Tab. I). A 29 de Janeiro de 1948 registou-se o valor máximo de precipitação diária anual (p.m.d.a.), $56 \mathrm{~mm}$ e um caudal de $2758 \mathrm{~m}^{3} / \mathrm{s}$, enquanto que a 30 de Dezembro de 1961, com 79,3 mm de p.m.d.a., o QMI foi efectivamente superior, mas o caudal médio foi de $1707 \mathrm{~m}^{3} / \mathrm{s}$. Comparando esta situação com a de 27 de Janeiro de 2001 (ainda que com período de regularização antecedente), os 58 mm de p.m.d.a. proporcionaram um QMI mais reduzido, mas um caudal diário superior, de $1778,7 \mathrm{~m}^{3} / \mathrm{s}$. Em várias situações se destaca a grande causa - os meses "chuvosos" ou "muito chuvosos", que se repercutem em caudais mais ou menos abundantes (Tab. I). 


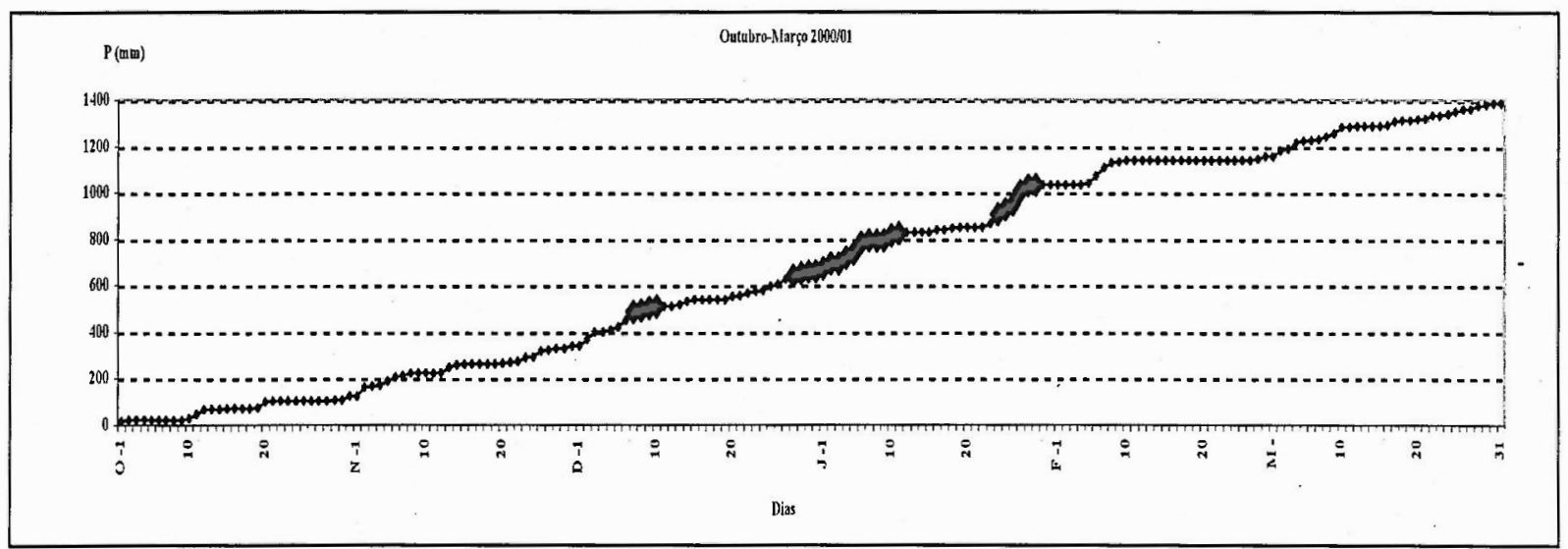

Figura 5 - Distribuição dos dias de cheia "significativa" sob precipitação acumulada, em 2000/01. Fonte: INAG, NAC e IGUC.

\section{Definição de categorias de risco de cheia e de perigo de inundação}

No século XX, as cheias foram "o desastre natural mais mortífero em Portugal" (C. RAMOS, E. REIS, 2001, p. 61) e porque constituem, na época chuvosa, o risco natural "mais frequente em Portugal, relativamente ao meio geográfico em que actuam" (L. LOURENÇO, 1996, p. 37), é necessário gerir o risco de cheia e, em particular, no Baixo Mondego, onde o risco de cheia e de inundação está presente, como se comprova com a análise efectuada nas secções de referência estudadas.

Após a análise do comportamento hidrológico do rio, enquadrado na situação pluviométrica e hidrométrica antecedente e, ainda, com base em registos de imprensa local, foi esboçada uma tipologia de situações de risco de cheia "significativa" e de inundação - sob regularização dos caudais (Tabelas II e III) que possa vir a ser útil na actualidade, designadamente na previsão e gestão deste risco.

Considerou-se que o risco de "cheia significativa" é reduzido perante valores inferiores ao $5^{\circ}$ decil (mediana) do mês de maior caudal e máximo para valores iguais ao $9^{\circ}$ decil $\left(637 \mathrm{~m}^{3} / \mathrm{s}\right.$ em regime natural e $682,7 \mathrm{~m}^{3} / \mathrm{s}$, em regime regularizado) (tab. II). Isto significa que valores próximos do $9^{\circ}$ decil se aproximam do limiar do risco de "cheia significativa" e da situação de perigo de inundação, que em função das características desta, a verificar-se, poderá ou não desencadear situação de crise.

\begin{tabular}{|c|c|}
\hline Q cheia em Coimbra*( Decil ) & Risco de "cheia significativa" \\
\hline$\left[1^{\circ}, 5^{\circ}[\right.$ & Reduzido \\
\hline$\left[5^{\circ}, 7^{\circ}[\right.$ & Moderado \\
\hline$\left[7^{\circ}, 8^{\circ}[\right.$ & Elevado \\
\hline$\left[8^{\circ}, 9^{\circ}[\right.$ & Muito Elevado \\
\hline $9^{\circ}$ & Máximo \\
\hline
\end{tabular}

Tabela II - Classes de risco de cheia.

Fonte: DGSH, INAG, NAC; IGUC

* Pt Sta Clara / Açude Pt

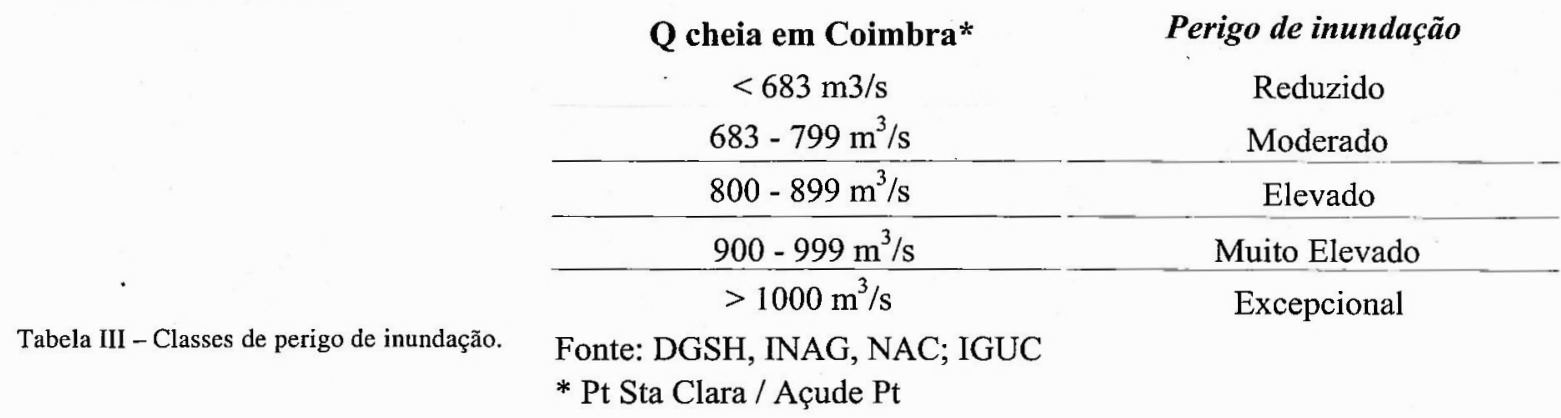


Em termos de perigo de inundação, para valores inferiores ao $9^{\circ}$ decil (aproximadamente $683 \mathrm{~m}^{3} / \mathrm{s}$ ), ele é reduzido em Coimbra. Do $9^{\circ}$ decil e até valores de caudal diário da ordem dos $799 \mathrm{~m}^{3} / \mathrm{s}$, o perigo passa a moderado; de 800 a $899 \mathrm{~m}^{3} / \mathrm{s}$ é elevado; de 900 a $999 \mathrm{~m}^{3} / \mathrm{s}$ é muito elevado. Para valores iguais ou superiores a $1000 \mathrm{~m}^{3} / \mathrm{s}$, reveste um carácter excepcional (tab. III).

A classe de perigo associada aos $1000 \mathrm{~m}^{3} / \mathrm{s}$ é indirectamente confirmada pelos valores atingidos em Janeiro de 1973, sob regime natural e Dezembro de 1989, com caudal regularizado. Acima destes valores ocorrerá inundação nas cotas mais baixas junto à cidade, como no Choupalinho e margem direita à mesma cota. Isto corresponde a situação de crise, que será tanto mais prejudicial, quanto maior o nível atingido pelas águas do rio.

De acordo com as categorias de risco e de perigo estabelecidas mediante a amostra estudada, a situação de Janeiro de 2001 revestiu-se de um carácter de excepcionalidade, traduzida por uma crise de inundação em certas áreas da cidade (Fig. 6) e, sobretudo, em vastas áreas do Baixo Mondego (Fig. 7), com consequências que levarão vários anos a recuperar, um problema que se pensava ter debelado com a regularização do Mondego.

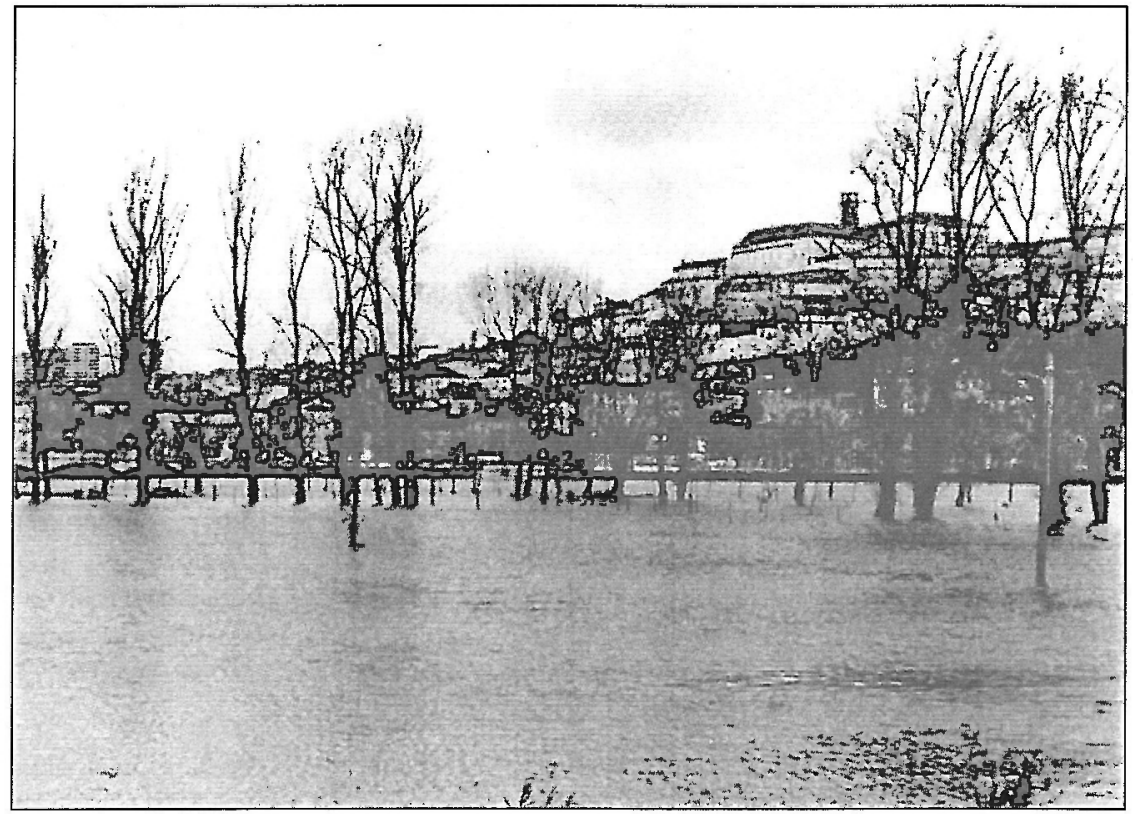

Figura 6 - Inundação em Coimbra (Praça da Canção), em Janeiro de 2001

Fonte: Arquivo da Casa da Cultura.

Figura 7 - Isolamento da povoação da Ereira e inundação dos campos envolventes, em 29 de Janeiro de 2001. Fonte: Eng. ${ }^{\circ}$ C. Batista, NAC.

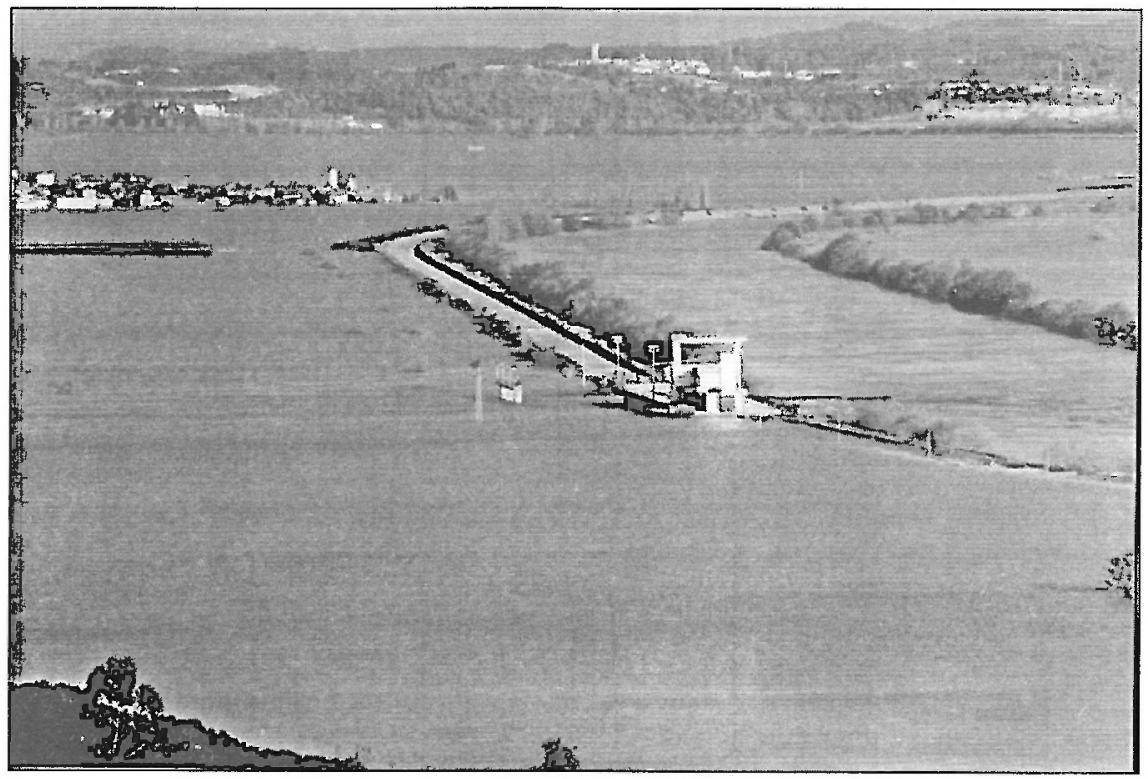


Quando,emespaços ribeirinhos, pretendemos regular o uso do solo, háque terem conta, segundo A. MIRABET e E. RIBAS (1994, p. 157), três áreas, sendo de:

- proibição, para que não haja obstáculos à corrente, pois trata-se de áreas de inundações frequentes;

- restrição, em áreas adjacentes às anteriores, vulneráveis a inundações extraordinárias;

- precaução, para áreas com inundações de rara frequência, servindo apenas como cota de referência para precaução dos proprietários.

Na sequência da análise e classificação do comportamento hidrológico do rio, em Coimbra, torna-se pertinente divulgar a cartografia das áreas inundáveis, de "precaução" e de "restrição", quanto à sua ocupação humana. Estas correspondem, respectivamente, às que foram afectadas pelas maiores inundações, tanto em período de caudal natural, 29 de Janeiro de 1948, como de caudal regularizado, de 27 de Janeiro de 2001 (fig. 8).

\section{Considerações finais}

A jusante da ponte da Portela, em Coimbra, com estações chuvosas precoces, prolongadas e intensas, a susceptibilidade de ocorrência de cheia "significativa" poderá ter início a partir do mês de Dezembro. Em situação de meses "chuvosos" acompanhados de outros "excessivamente chuvosos", os caudais médios mensais serão também muito elevados e/ou excepcionais. Nesta situação, no período de Inverno, o correspondente ao de maior risco de inundação, verificámos que os espaços de cotas mais baixas correspondentes ao leito de inundação ficam sujeitos à abundância fluvial, que será tanto mais gravosa, quanto maior

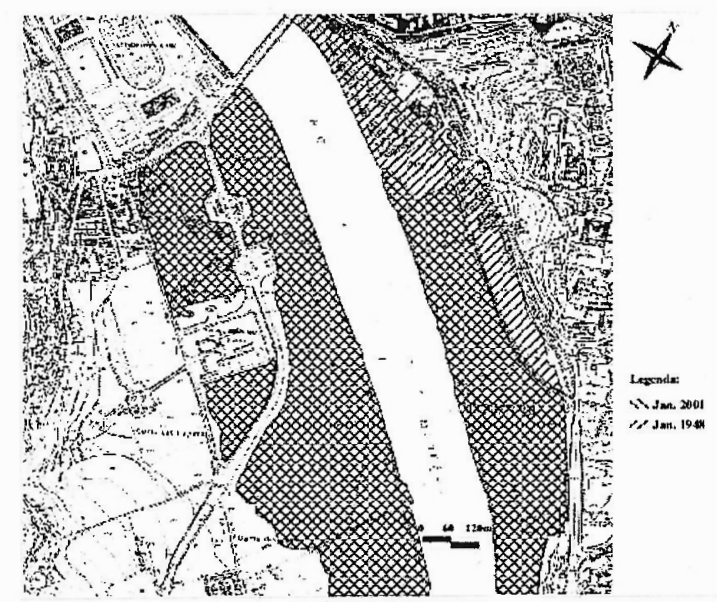

Figura 8 - Representação das áreas de "restrição" (Janeiro de 2001) e de "precaução" (Janeiro de 1948) com base nas maiores inundações em Coimbra (Secção de referência: Ponte de Sta Clara - Coimbra), com caudal natural (1948) e com caudal regularizado (2001). for a ocupação humana e a altura de água em cada uma das secções consideradas.

Torna-se, deste modo, evidente a urgência do planeamento e do ordenamento do espaço drenado pala bacia hidrográfica do rio Mondego, propondo diferentes alternativas para o uso dos solos, do mesmo modo que se torna imperioso o cumprimento da legislação, a fiscalização, a aplicação de "normas de resultados" e ainda, concluir e manter com elevados padrões de operacionalidade a regularização do caudal do Mondego e dos seus afluentes. Desta forma, contribuir-se-á para o pretendido desenvolvimento do Baixo Mondego, o qual poderá proporcionar à respectiva população a qualidade de vida desejada.

\section{Referências bibliográficas:}

BATEIRA, Carlos e SOARES, Laura (1997) - "Movimentos em massa no norte de Portugal. Factores da sua ocorrência". Territorium, Coimbra, 4, MinervaCoimbra, p. 63-77.

DIRECÇÃO GERAL DOS SERVIÇOS HIDRÁULICOS E ELÉCTRICOS (1936) - Anuário dos Serviços Hidráulicos, Imprensa Nacional, Lisboa, p. 51.

LENCASTRE, A.; FRANCO, F. M. (1984) - Liçôes de Hidrologia. Universidade Nova de Lisboa, p. 284.

LOURENÇO, Luciano (1986) - "Aproveitamento hidráulico do vale do Mondego". Problemas do vale do Mondego, IV Colóquio Ibérico de Geografia, Coimbra.

LOURENÇO, Luciano (1996) - "Coimbra e os Riscos Naturais. Passado e Presente". Cadernos de Geografia. n. ${ }^{\circ}$ Especial, Coimbra, p. 37-43.

LOURENÇO, Luciano; LEMOS, Luís (2001) - "Considerações acerca da movimentação em massa ocorrida na vertente poente da Av. Elísio de Moura, em Coimbra". Territorium, Coimbra, 8, MinervaCoimbra, p. 83-108.

LOURO, Sílvia (2004) - Condições meteorológicas com efeitos de inundação. O exemplo da Bacia do Mondego. Dissertação de Mestrado em Geografia, Faculdade de Letras da Universidade de Coimbra, Coimbra, 150 p. (inédito).

MIRABET, Armand G.; RIBAS, Enric S. (1994) - "La cartografia del risc d'inundatió. Una eina per a la planificació", Documents d'anàlise geográfica, 24, p. 149-167.

QUINTELA, António C. (1986) - "O Mondego na hidráulica fluvial portuguesa até ao século XX". História e desenvolvinento da ciência em Portugal, Vol. II, Lisboa, p. 1026.

RAMOS, Catarina e REIS, Eusébio (2001) - "As cheias no sul de Portugal em diferentes tipos de Bacias hidrográficas". Finisterra, XXXVI, 71, Lisboa, p. 60-82.

RIBEIRO, Orlando; LAUTENSACH, Hermann; DAVEAU, Suzanne (1994)-Geografiade Portugal. Oritmoclimáticoe a paisagem. Volume II, Lisboa, Ediçōes João Sá da Costa. 